\title{
1 Effect of the Crystal Size of Biogenic Hydroxyapatites on IR and Raman Spectra
}

2 S.M. Londoño-Restrepo ${ }^{1}$, L. F. Zubieta-Otero ${ }^{1}$, R. Jeronimo-Cruz ${ }^{1}$, M. A. Mondragon ${ }^{2}$, and

3 M. E. Rodriguez-García,

4

$5 \quad$ RUNNING TITLE: Optical properties of hydroxyapatites

6

7

8

9

10

11

12

13

14

15

16

17 


\section{ABSTRACT}

This work focuses on the analysis of the impact that raw and calcined biogenic

hydroxyapatite crystal size has on the Raman and infrared spectra. To this end, bovine,

porcine, and human bones samples were defatted and deproteinized as well as calcinated at $720^{\circ} \mathrm{C}$ and then analyzed through Raman and Infrared spectroscopies, Transmission

Electron Microscopy (TEM), Inductively Coupled Plasma (ICP), and Scanning Electron

Microscopy (SEM). Raman and IR spectra for raw samples showed broad bands while after calcination bands became narrow and well defined. TEM images showed that all raw crystallites are nano-plates with a high crystalline quality contrary to the so far wellestablished concept that biogenic hydroxyapatites have low crystalline quality. This fact confirmed that the broad Raman and infrared bands of raw clean bones come from nanocrystal-plates. SEM analysis confirmed the increase in the size of the crystals after calcination from nano to sub-micron dimensions due to a coalescence phenomenon. 


\section{INTRODUCTION}

41 Nowadays bio-ceramic materials like hydroxyapatites are growing in importance in

42 different fields, particularly in tissue engineering for medical and dental applications. The

43 hydroxyapatite obtained from natural sources is called bio-hydroxyapatite (BIO-HAp), and

44 its main difference with synthetic apatites is that it is a carbonated hydroxyapatite which

45 contains other elements such as $\mathrm{Na}, \mathrm{Mg}, \mathrm{Mn}, \mathrm{Fe}$, among others $(1,2)$.

46 The physicochemical characterization of raw bone as well as BIO-HAp obtained through

47 different methodologies is still an open problem due to the complexity of the material.

48 Infrared and Raman spectroscopies have been extensively used to study these materials to

49 monitor the removal of the organic matrix from the mineral phase as well as to identify

50 different mineral phases and to study the changes in the crystalline quality of HAp caused

51 by thermal processes $(3,4)$. However, no studies about the influence of the crystal size on

52 the vibrational properties of synthetic and natural hydroxyapatites have been reported in

53 detail. Usually, when these spectroscopies are used to study the vibrational states in

54 synthetic and natural hydroxyapatites (5), the full width at the half maximum (FWHM) of a

55 characteristic peak is used to determine the crystalline quality of HAp crystals and for

56 clinical diagnostic (6). However, this criterion must be discussed in detail in the case of

57 nanostructures.

58 It is well established in the literature that nanosized crystals produce wider Raman bands

59 than micro-sized ones as can be found for semiconductors as $\mathrm{Si}(7,8)$. The phonon

60 confinement model has been proposed to explain Raman spectra in nanosized systems

61 because the surface states must be considered (9-12). According to Gao et al. (13), the

62 underlying mechanism behind the size-dependent Raman shifts is still quite controversial 
63 and an open problem. They proposed a theoretical method to explain the quantum

64 confinement effects on the Raman spectra of semiconductor nanocrystals indicating that the

65 shift of Raman bands in nanocrystals results from two overlapping effects: the quantum

66 effect shift and a surface effect shift. Their calculations showed that there is a small shift in

67 peak position as a function of the crystal size. On the other hand, they proposed this model

68 for using Raman spectroscopy as a tool to measure size in nanostructures. Different works

69 related to the Raman characterization of nano-synthetic HAp have been published in which

70 the width of the band was not considered in the Raman interpretation. Concerning the

71 analysis of the FWHM of Raman bands, Wopenka and Pasteris (14) showed that the

72 significantly wider bands for biomaterials are indicative of the shorter-range disorder these

73 nanocrystalline and carbonated phases have in comparison to those of synthetic

74 hydroxyapatites. Even though they found that the studied biomaterials are in the nanoscale

75 range, they did not consider that in nanoscale materials Raman dispersion is governed by

76 surface states. The translational symmetry of the crystal is broken at grain boundaries

77 which results in the appearance of specific surface and interface vibrational contributions

78 (15). However, in the case of bio-hydroxyapatites, this information is still under discussion.

79 For the determination of crystallinity in bones using Raman, the most used parameter is the

80 width of the phosphate band at $959 \mathrm{~cm}^{-1}$ because it is an intense band with no overlapping

81 from other bands $(5,16,17)$. The calculation of the FWHM is carried out using a single

82 Gaussian curve to fit the mentioned band. The fitted FWHM value is reported in

83 wavenumbers, and its inverse is considered as a parameter that determines the crystalline

84 quality of the samples. Nevertheless, this calculation does not make any physical sense

85 when the particles are at the nano-scale. 
FT-IR and Raman spectroscopy have also been used to quantify bone mineral crystallinity.

Querido et al. (18) developed a methodology based on the ratio between selected bands to determine bone crystallinity. The X-ray diffraction peaks of the studied bones according to their interpretation had poor crystallinity thus resulting in broad and overlapping peaks.

Nonetheless, this is misleading because it is well known that for nanoparticles, their X-ray diffraction patterns are formed by simultaneous and non-separable scattering and diffraction phenomena. Concerning the Raman analysis of the same samples, they found that the Raman bands varied in width and position due to the different degrees of crystallinity, but they did not perform the study of the crystalline quality of the samples by TEM.

The analyses of calcium phosphates by vibrational spectroscopies have been performed both from a theoretical and experimental point of view (19). According to De Mul et al. (17), the line broadening of the IR spectrum is related to the irregularity of the atomic array, referred to as lattice strain, among others. On the other hand, they consider that the crystallinity of the apatite domains can be determined by XRD. This kind of determination at a microscopic scale is difficult, so they chose a crystallinity index obtained from the broadening of the $v_{4}$ apatite band at $600 \mathrm{~cm}^{-1}$. Here, it is essential to point out that the crystal size effects (finite crystal and surface states) are not considered. The same group made the calculation of the IR broadening with a relatively simple inter- and intra-ionic potential (Coulombian) in which all atoms have the same number of bonds, but the surface states break this rule and must be incorporated into the calculation.

Considering the above references, the aim of this work was to study the influence of the crystal size on the Raman and infrared spectra of hydroxyapatites from bovine, porcine and 
109 human bones to establish criteria to determine the size and crystalline quality of the

110 synthetic HAp and BIO-HAp through FWHM measurements.

\section{MATERIAL AND METHODS}

\section{Raw bone and annealed samples}

114 Cortical bones from bovine, porcine, and human femurs were used for this work. Human

115 femurs without any apparent pathologies were provided by the Universidad Autónoma de

116 Querétaro while bovine bones (3-years-old) and porcine bones (157 days) were collected

117 from the local slaughterhouse (folio number SDA-537295-98, 2017). All bones were

118 defatted and deproteinized using the procedure proposed by Londoño-Restrepo et al., (1) in

119 brief: the soft tissues of pre-cut $3 \mathrm{~cm}$ long bone slices were removed using a hydrothermal

120 treatment with distilled water in an All Americans $1915 \mathrm{X}$ autoclave at $127^{\circ} \mathrm{C}$ and $1.5 \mathrm{~atm}$

121 for $40 \mathrm{~min}$ three times. Subsequently, bones were dried off at $90{ }^{\circ} \mathrm{C}$ for $48 \mathrm{~h}$ to facilitate the

122 grinding process. These bones were pulverized and sieved in a US 200 mesh $(75 \mu \mathrm{m})$ to

123 obtain powders with particles smaller than $75 \mu \mathrm{m}$. Finally, the bone powders were

124 subjected to an alkaline hydrothermal treatment in a $\mathrm{Ca}(\mathrm{OH})_{2}$ solution (Mallincrodt Baker

125 CAS No 1305-62-1) to remove the protein. Raw samples were labeled as B-Raw for

126 bovine, P-Raw for porcine, and H-Raw for human. Afterward, the samples were incinerated

127 at the same time using a Felisa (Mexico) furnace at $720{ }^{\circ} \mathrm{C}$ at a heating rate of $6{ }^{\circ} \mathrm{C} / \mathrm{min}$ and

128 a sintering time of $10 \mathrm{~min}$ as is shown in the thermal profile (Fig.1) and later cooled

129 inertially into the furnace in presence of air $(20,21)$. The annealed samples were labeled as

130 B-720 for bovine, P-720 for porcine, and H-720 for human. On the other hand, a synthetic 
131 sample of hydroxyapatite from Sigma Aldrich was used in this study for comparative

132 propose.

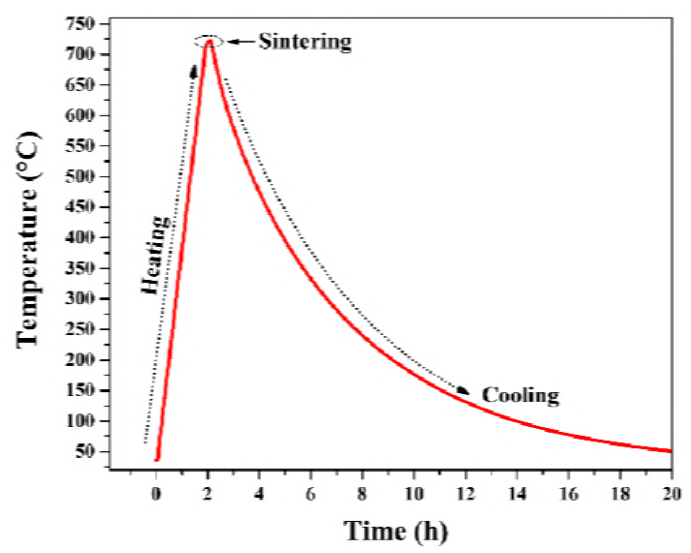

134 Figure 1. Thermal profile for powder bones incinerated at $720^{\circ} \mathrm{C}(\mathrm{B}-720, \mathrm{P}-720$, and $\mathrm{H}-$ 135 720).

137 Mineral content: ICP

138 To determine the dependence of the vibrational spectra of raw bones on the different

139 chemical elements they may have, the mineral composition of the untreated and calcinated

140 samples was determined. Thus, the elemental composition of the BIO-HAp from human,

141 bovine, and porcine bones, was determined with the use of a Thermo Fischer Scientific

142 ICAP 6000 Series equipment with an argon plasma. $0.1 \mathrm{~g}$ of each sample was digested with

$1437 \mathrm{~mL}$ of nitric acid (Baker $69.3 \%$ ) using a temperature program; samples were analyzed in

144 duplicate. Afterward, the samples were filtered (Whatman No. 42) and their volume was

145 completed to $100 \mathrm{~mL}$ with deionized water. Finally, the samples were exposed to the argon

146 plasma to excite the elements in the samples to identify them through their characteristic 
147 emission spectra. These were converted to elemental content by comparison to standard

148 curves.

\section{Infrared spectroscopy}

151 Infrared spectroscopy was used to follow the cleaning process aimed to defat and

152 deproteinize the bones until the complete removal of the organic phase as well as to

153 determine the influence of the crystal size on the infrared spectra of raw samples and

154 samples incinerated at $720^{\circ} \mathrm{C}$. The measurements were performed on a 6700 FTIR Thermo

155 Scientific spectrometer equipped with an ATR (Attenuated Total Reflectance) accessory

156 with a diamond crystal in the spectral range of 400 to $4000 \mathrm{~cm}^{-1}$ at a spectral resolution of 4 $157 \mathrm{~cm}^{-1}$.

\section{Raman spectroscopy}

160 All bone samples were analyzed using a Senterra Raman spectrometer from Bruker,

161 equipped with a $785 \mathrm{~nm}$ laser and an Olympus microscope. A 20X objective was used, the

162 spectral range measured was from 70 to $3500 \mathrm{~cm}^{-1}$, with a resolution of $3 \mathrm{~cm}^{-1}$ and the

163 following instrument parameters: a $50 \mu$ aperture, $100 \mathrm{~mW}$ of laser power of, $6 \mathrm{~s}$

164 integration time and 6 scans.

\section{TEM characterization}


167

168

169

170

171

172

173

174

175 deposited on them.

176

\section{RESULTS}

178

179

180

181

182

183

184

185

186 187 determinations. The crystal sizes obtained were: $21.35 \pm 7.76 \mathrm{~nm}$ long and $6.03 \pm 1.42 \mathrm{~nm}$

TEM images of B-Raw, P-Raw, and H-Raw were obtained. A high-resolution transmission electron microscope (S) TEM (JEOL ARM200F) was used to determine the crystal size of the bio hydroxyapatite samples; the acceleration voltage was $200 \mathrm{kV}$.

\section{Morphological studies of incinerated samples: SEM}

Morphologic analysis of all BIO-HAp samples calcined at $720^{\circ} \mathrm{C}$ was carried out in a Jeol JSM 6060LV Scanning Electron Microscope, with an electron acceleration voltage of 20 $\mathrm{kV}$. The samples were fixed on a copper holder with carbon tape and a gold thin film was

\section{TEM characterization}

Fig. 2 shows TEM images for defatted and deproteinized samples: P-Raw (A-D), B-Raw (E-H), and H-Raw (I-L). Here, it is very important to point out that according to Fig. 2 C, $\mathrm{G}$, and $\mathrm{K}$ the bone from porcine, bovine, and human are formed by nano-plates. On the other hand, Fig. 2. B, F, and J clearly show that these BIO-HAps are in fact highly crystalline structures.

The images in Fig. 2 C, G, and $\mathrm{K}$ show that bones are formed by a polycrystalline arrangement of crystalline HAp nano-plates. The crystal size (2D) of these samples was determined using Image $\mathbf{J}$ software and are reported as the average value of 25 
bioRxiv preprint doi: https://doi.org/10.1101/465146; this version posted November 7, 2018. The copyright holder for this preprint (which was not certified by peer review) is the author/funder, who has granted bioRxiv a license to display the preprint in perpetuity. It is made available under aCC-BY-NC-ND 4.0 International license.

188 wide for human samples, $12.92 \pm 2.55 \mathrm{~nm}$ long and $7.09 \pm 1.05 \mathrm{~nm}$ wide for bovine samples

189 and $16.53 \pm 3.56 \mathrm{~nm}$ long and $6.37 \pm 0.32 \mathrm{~nm}$ wide for porcine samples.
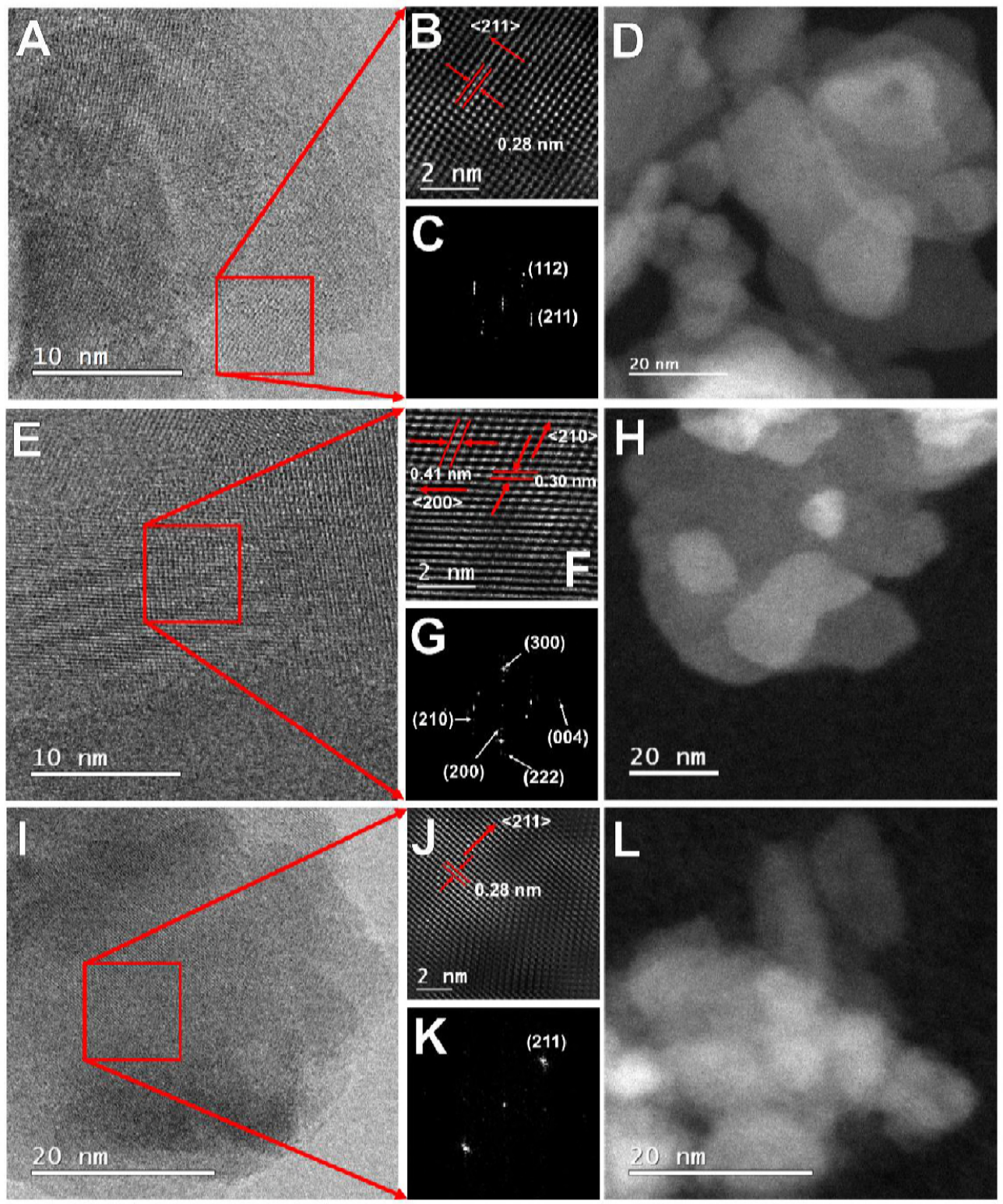

192 Figure 2. TEM images of the defatted and deproteinized porcine (A-D), bovine (E-H) and

193 human (I-L) bones. 

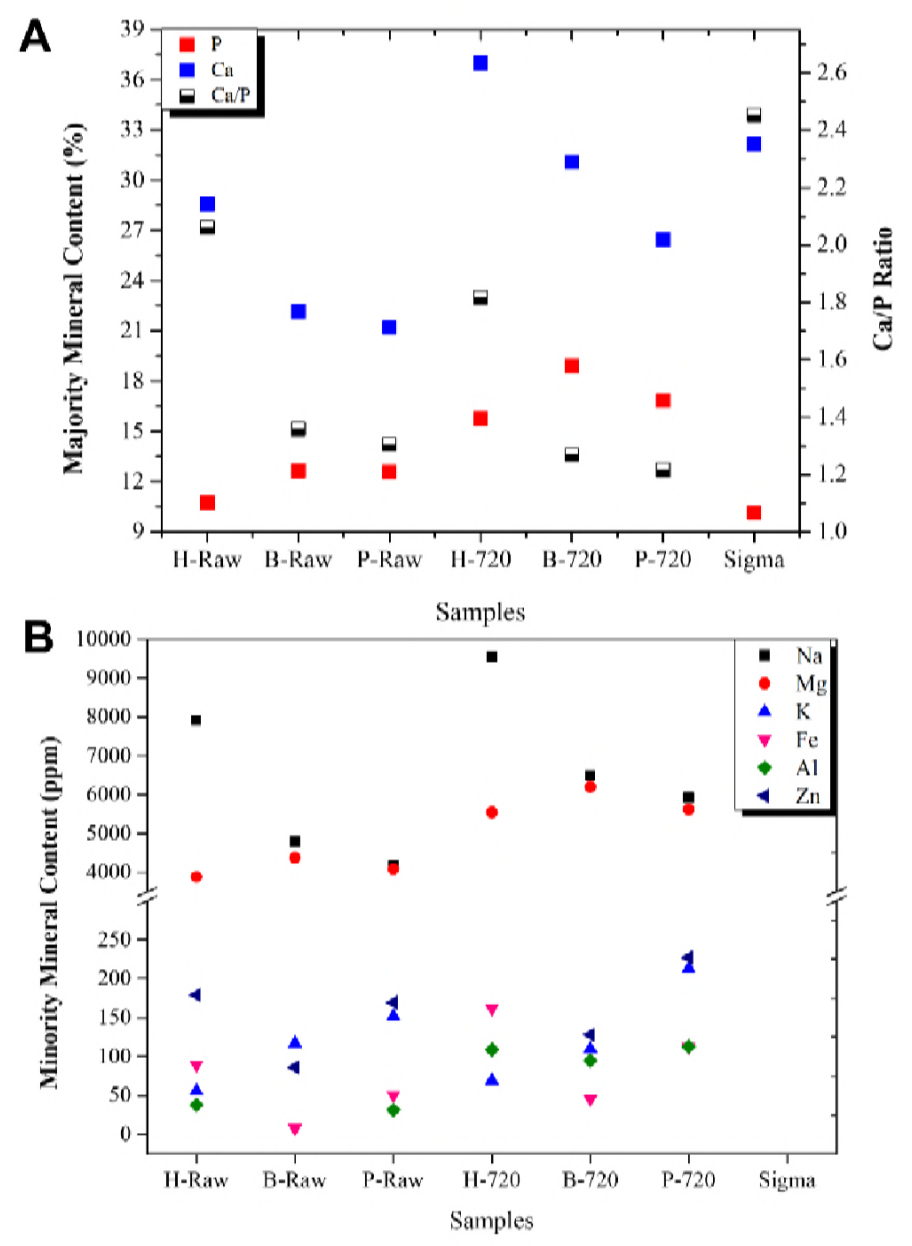

196 Figure 3. Mineral composition of defatted and deproteinized human, bovine and porcine

197 powder bone. (A) Content of major minerals, $\mathrm{P}$ and $\mathrm{Ca}$ and $\mathrm{Ca} / \mathrm{P}$ ratio. (B) Content of 198 minor minerals: $\mathrm{Na}, \mathrm{Mg}, \mathrm{K}, \mathrm{Fe}, \mathrm{Al}$, and $\mathrm{Zn}$.

200 Fig. 3 A shows the $\mathrm{P}$ and Ca content and the Ca/P ratio for all samples: P-Raw, B-Raw, H-

201 Raw, P-720, B-720, H-720, and synthetic HAp from Sigma-Aldrich. Ca percentage is from

20221 to $37 \%$ while the P content is from 9 to $19 \%$. Stoichiometric hydroxyapatite has 39.89

$203 \% \mathrm{Ca}$ and $18.5 \% \mathrm{P}$. In the same way, $\mathrm{Ca} / \mathrm{P}$ ratio varies from 1.2 to 2.4 when is 1.67 for 
204

205

206

207

208

209

210

stoichiometric hydroxyapatite. Moreover, biogenic hydroxyapatites exhibit trace elements as $\mathrm{Na}, \mathrm{Mg}, \mathrm{K}, \mathrm{Fe}, \mathrm{Al}$, and $\mathrm{Zn}$ with a maximum value of $9500 \mathrm{ppm}(0.95 \%)$.

\section{IR vibrational analysis}

Fig. 4 A to D shows the IR bands located between 400 to $4000 \mathrm{~cm}^{-1}$ for raw and calcinated samples, and Sigma Aldrich. The letters correspond to the identification carried out in this work, and these values were compared with others found in the literature in Table 1.
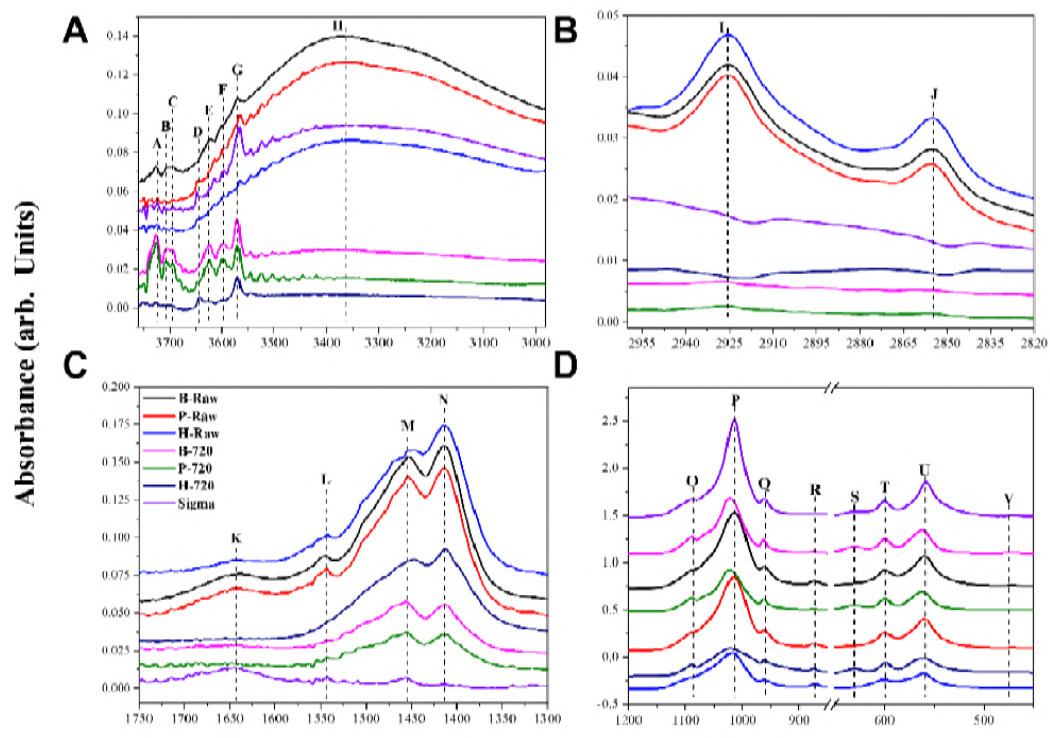

Wavenumber $\left(\mathrm{cm}^{-1}\right)$

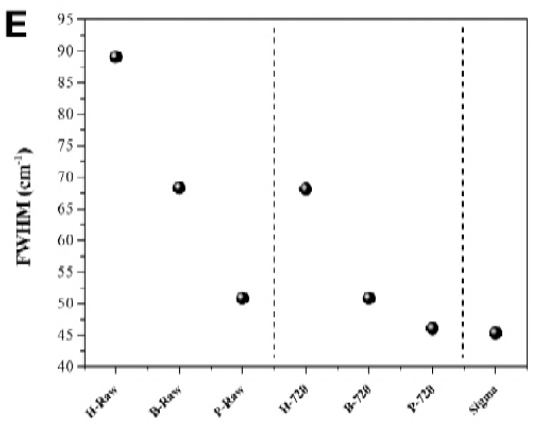

212 Figure 4. Infrared spectra of raw and calcined samples from human, bovine and porcine

213 bones, as well as synthetic Hap, in the spectral ranges: (A) $3700-3000 \mathrm{~cm}^{-1}$, (B) 2955-2820 
$214 \mathrm{~cm}^{-1}$, (C) $1750-1300 \mathrm{~cm}^{-1}$, (D) $1200-450 \mathrm{~cm}^{-1}$, and (E) FWHM of $560 \mathrm{~cm}^{-1}$ band for all

215 samples analyzed.

216 Fig. 4. E shows the FWHM for raw and calcined samples, considering the band at $560 \mathrm{~cm}^{-1}$.

217 After calcination, clearly the $560 \mathrm{~cm}^{-1}$ band becomes narrow and well defined. Some bands

218 shown in Table 1 correspond to organic material and adhered water in the samples which

219 disappear after calcination as H, I, J, K, and L bands (see Fig. 4 C). Regarding Sigma

220 Aldrich sample, it does not exhibit any carbonate band then it is clear that this sample is a

221 non-carbonated hydroxyapatite that contains a carbonyl group. The A, B, and C bands are

222 presented in the studied samples. However, the origin of these bands is not understood.

224 Table 1. Observed infrared band positions for raw bones, sintered hydroxyapatites, and

225 Sigma Aldrich.

\begin{tabular}{|c|c|c|c|}
\hline \multicolumn{4}{|c|}{ FT-IR Spectroscopy } \\
\hline Functional Group & Wavenumber $\left(\mathrm{cm}^{-1}\right)^{*}$ & Wavenumber $\left(\mathrm{cm}^{-1}\right)$ & Reference \\
\hline v O-H (HAp) & (D) $3645^{a b}$ & $3642-44$ & {$[22,23]$} \\
\hline$v-\mathrm{COOH}$ & (G) $3570^{a b c}$ & 3571 & [24] \\
\hline $\begin{array}{c}v \mathrm{O}-\mathrm{H} \\
\left(\text { Absorbed } \mathrm{H}_{2} \mathrm{O}\right) \\
\end{array}$ & (H) $3375^{a c}$ & 3367 & [22] \\
\hline$v \mathrm{C}-\mathrm{H}$ & (I) $2925^{a}$ & 2923,2850 & [22] \\
\hline $\begin{array}{c}\text { Amide I } \\
(\mathrm{C}=\mathrm{O})\end{array}$ & (K) $1642^{a b}$ & $\begin{array}{l}1670 \\
1642 \\
\end{array}$ & $\begin{array}{l}{[25]} \\
{[26]}\end{array}$ \\
\hline Amide II & (L) 1543 & 1547 & [27] \\
\hline$v_{3 \mathrm{as}} \mathrm{CO}_{3}{ }^{2-}$ & $\begin{array}{l}\text { (M) } 1454^{a b c} \\
\text { (N) } 1412^{a b}\end{array}$ & $\begin{array}{c}1430,1457 \\
1417 \\
1415-6,1460-1 \\
\end{array}$ & $\begin{array}{l}{[26]} \\
{[24]} \\
{[22]}\end{array}$ \\
\hline$v_{1 \mathrm{~s}} \mathrm{CO}_{3}^{2-}$ & (O) $1088^{a b c}$ & 1089 & [28] \\
\hline$v_{3} \mathrm{PO}_{4}{ }^{3-}$ & (O) $1088^{a b c}$ & $\begin{array}{c}1043 \\
1033-5\end{array}$ & $\begin{array}{l}{[22]} \\
{[23]}\end{array}$ \\
\hline$v_{1} \mathrm{PO}_{4}^{3-}$ & (Q) $960^{a b c}$ & $\begin{array}{c}978 \\
960-3\end{array}$ & $\begin{array}{c}{[25]} \\
{[22,23,24]}\end{array}$ \\
\hline$v_{2 \mathrm{as}} \mathrm{CO}_{3}^{2-}$ & (R) $872^{a b}$ & $\begin{array}{c}875 \\
871-3 \\
\end{array}$ & $\begin{array}{c}{[26]} \\
{[22,24]}\end{array}$ \\
\hline $\begin{array}{c}\nu \mathrm{O}-\mathrm{H} \\
\text { Libration modes of HAp }\end{array}$ & (S) $630^{a b c}$ & $632-3$ & {$[23,25]$} \\
\hline $\mathrm{v}_{4} \mathrm{PO}_{4}^{3-2}$ & (T) $600 a b c$ & $\begin{array}{l}617,572 \\
563,602 \\
\end{array}$ & $\begin{array}{l}{[22]} \\
{[26]}\end{array}$ \\
\hline $\mathrm{v}_{2} \mathrm{PO}_{4^{3-}}$ & (V) $473^{a b c}$ & 476 & [25] \\
\hline
\end{tabular}

* This work. a.- Raw samples, b.- Calcined samples. c.- HAp from Sigma-Aldrich. $\mathrm{v}=$ stretching. 


\section{Raman vibrational analysis}

228 The Raman spectra of the two sets of samples, raw and calcined, which correspond to nano-

229 and micro-crystals, are displayed in Fig. 5, as for Sigma Aldrich hydroxyapatite. All found

230 Raman bands are shown in Table 2.
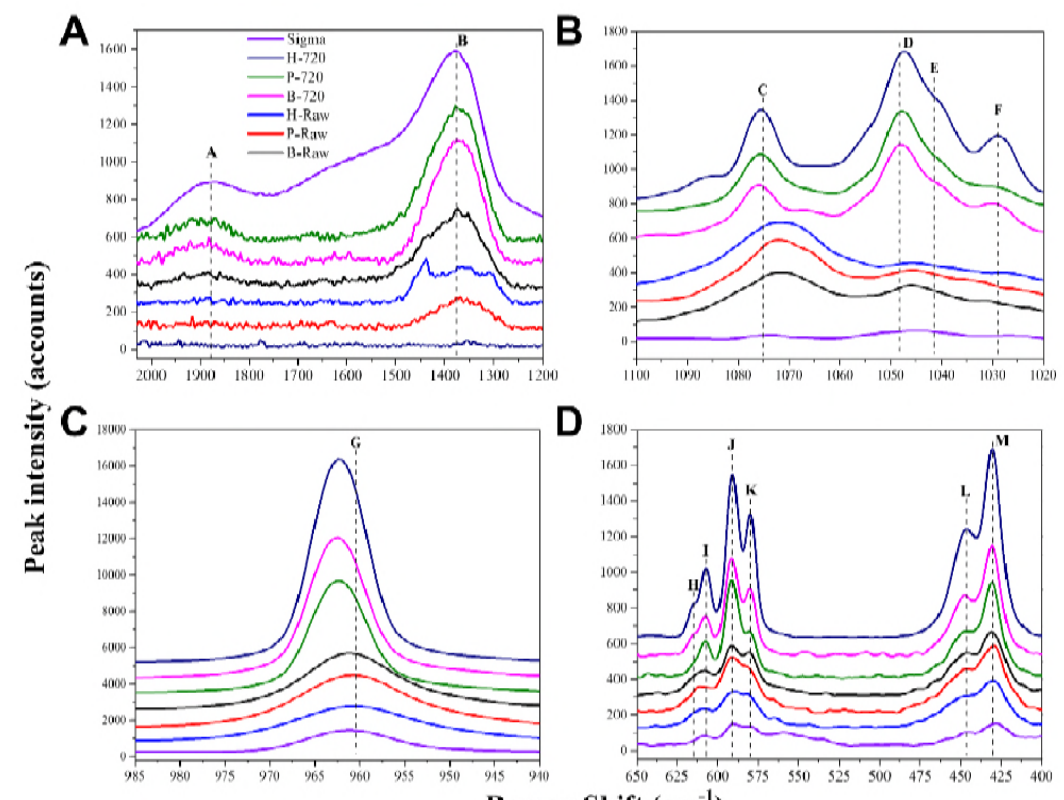

Raman Shift $\left(\mathrm{cm}^{-1}\right)$

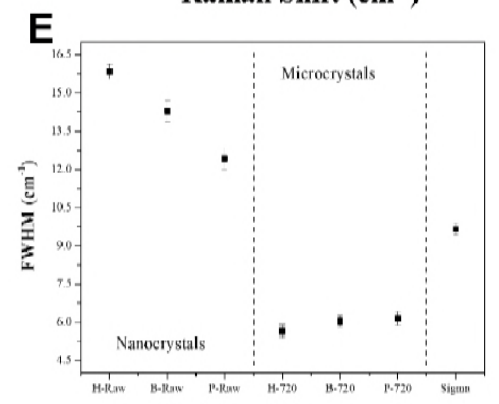

232 Figure 5. Raman spectra of raw and calcined samples from human, bovine and porcine

233 bones, as well as synthetic Hap, in the spectral ranges: (A) 2000-1200 $\mathrm{cm}^{-1}$, (B) 1100-1020

$234 \mathrm{~cm}^{-1}$, (C) $985-940 \mathrm{~cm}^{-1}$, (D) $650-400 \mathrm{~cm}^{-1}$, and (E) FWHM of $960 \mathrm{~cm}^{-1}$ band for all samples analyzed. 
236 As can be observed from this figure, raw samples for porcine, bovine, and human bones

237 have lower intensities and wider bandwidths as compared to those for the corresponding

238 calcined bone samples; the FWHM value for the synthetic HAp sample lies between the

239 values for the micro and nano samples.

241 Table 2. Observed infrared band positions for raw bones, sintered biogenic

242 hydroxyapatites, and Sigma Aldrich.

\begin{tabular}{|c|c|c|c|}
\hline \multicolumn{4}{|c|}{ RAMAN Spectroscopy } \\
\hline Functional Group & Wavenumber $\left(\mathrm{cm}^{-1}\right)^{*}$ & Wavenumber $\left(\mathrm{cm}^{-1}\right)$ & Reference \\
\hline Proteoglycan & (B) $1377^{a b c}$ & 1375 & [29] \\
\hline \multirow{4}{*}{$v_{3} \mathrm{PO}_{4}^{3-}$} & (C) $1076^{a b c}$ & 1076 & {$[16,30]$} \\
\hline & (D) $1048^{b}$ & $1045-8$ & {$[20,30,31,32]$} \\
\hline & (E) $1041^{b}$ & $1035,1041-3$ & {$[29,31]$} \\
\hline & (F) $1028^{b}$ & 1030 & {$[20,31]$} \\
\hline$v_{1} \mathrm{PO}_{4}^{3-}$ & (G) $960^{\text {abc }}$ & $\begin{array}{l}960-1 \\
955-7 \\
\end{array}$ & {$[20,30,31,33]$} \\
\hline$v_{4} \mathrm{PO}_{4}^{3+}$ & $\begin{array}{l}\text { (H) } 614^{\text {ab }} \\
\text { (I) } 6077^{\text {obc }} \\
\text { (J) } 591^{\text {abe }}\end{array}$ & $\begin{array}{c}579,591 \\
581 \\
587,609\end{array}$ & $\begin{array}{c}{[20,30]} \\
{[311]} \\
{[20,32]}\end{array}$ \\
\hline$v_{2} \mathrm{PO}_{4}^{3-}$ & $\begin{array}{l}\text { (L) } 446^{\circ b} \\
\text { (M) } 430^{\text {ab }}\end{array}$ & $\begin{array}{c}430-1,447-50 \\
425 \\
\end{array}$ & $\begin{array}{l}{[30,32]} \\
{[20,31]}\end{array}$ \\
\hline
\end{tabular}

\section{SEM analysis}

246 The effect of the incineration process on the crystal size of the calcined samples is showed

247 in Fig. 6 for P-720 (A), B-720 (B), and H-720 (C) samples. As was mentioned above, these

248 samples were calcinated at $720^{\circ} \mathrm{C}$ using the same thermal profile. Fig. 2 showed that the

249 raw samples are nanoplates with dimension around $20 \mathrm{~nm}$ length and 5 to $7 \mathrm{~nm}$ thick. After

250 calcination, these samples get the following sizes: $70.38 \pm 24.06 \mathrm{~nm}$ length and $45.52 \pm$

$2519.82 \mathrm{~nm}$ width for porcine sample, $52.31 \pm 15.16 \mathrm{~nm}$ length and $36.58 \pm 7.76 \mathrm{~nm}$ width for 
252 bovine sample, and finally $188.89 \pm 74.53 \mathrm{~nm}$ length and $173.33 \pm 48.25 \mathrm{~nm}$ width for

253 human.
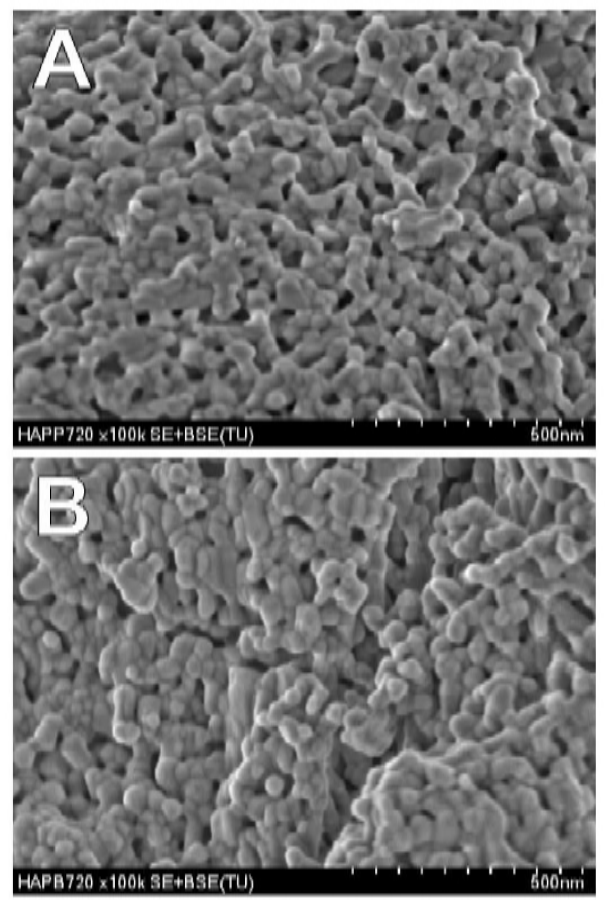

255 Figure 6. SEM image s of (A) P-720, (B) B-720, and (C) H-720.

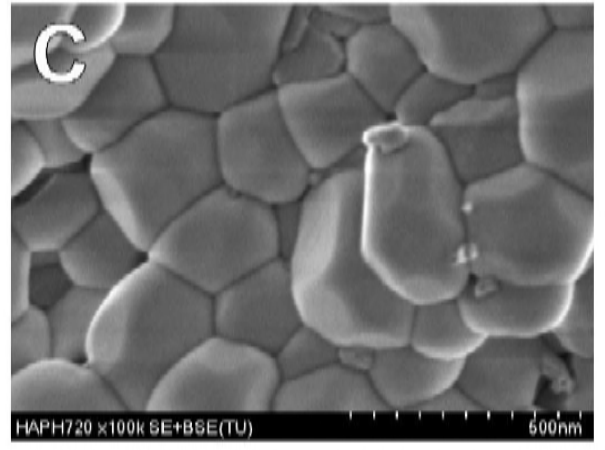

258 Results obtained from TEM analysis confirmed the nano-dimensions of the hydroxyapatite 
260

261

262

263

264

265

266

267

268

269

270

271

272

273

274

275

276

277 calcium value is the highest and its $\mathrm{Ca} / \mathrm{P}$ ratio is higher than for a stoichiometric

278 hydroxyapatite. Fig. 3 B exhibits the content of the minority elements in the bone which

279 can be located as substitutional or interstitial atoms. Physicochemical properties, in special

280 281 ions because they modify the chemical environment which in turn modifies the dipolar 282 moment and the polarizability. Here, it is worth noting that Sigma-Aldrich sample does not

with the well-known longitudinal and preferential growth of the bone (1). TEM analyses showed the presence of well-defined nanocrystals and the (112) and (002) planes for bovine bone, (211) for porcine, and (112) for human, thus indicating a high crystalline order for all bone samples. Patel et al. (34) pointed out that raw bone powder from bovine is crystalline based on TEM images. As was mentioned before, the nano-sized dimensions of the hydroxyapatite crystals from all these bones, have a strong influence on the vibrational properties of bone.

Biogenic hydroxyapatites are no stoichiometric as was demonstrated through ICP, but this is not a disadvantage since these traces help to osteoinductivity when this material is used for medical applications. Ca levels for human samples are higher than for bovine and porcine due to the age of the bones where the samples were obtained; bovine and human samples correspond to adults while porcine is from young animals (5 months old). Other

factors as diet, gender, and exercise can also modified their chemical composition (35). The difference in $\mathrm{Ca}$ and $\mathrm{P}$ levels between raw bones and calcined samples is due to a concentration effect since raw bone also contain small quantities of organic material. This fact directly affects the $\mathrm{Ca} / \mathrm{P}$ ratio that is 1.67 for stoichiometric hydroxyapatite, as can be seen in Fig. 3 A. In the case of Sigma-Aldrich hydroxyapatite sample, it was found that its the structural and vibrational ones of biogenic HAp are affected by the presence of these

283 contain other minority elements. 
284 As was showed before in Fig. 2, hydroxyapatite crystals from porcine, bovine, and human

285 bones are constituted as nano-plates with sizes that vary from 5 to $30 \mathrm{~nm}$ length and from 5

286 to $7 \mathrm{~nm}$ width. The calculations to obtain the vibrational frequencies of a crystalline system

287 assumes an infinite crystal size. However, in the case of nano-crystals, some atoms are

288 located within the crystal and their coordination number on average is the same, while

289 atoms on the surface exhibit different coordination numbers. Considering this fact, it is

290 expected that the characteristic bands for the vibrational transitions producing the Raman

291 and infrared spectra of hydroxyapatites suffer changes in position and width as compared

292 with crystals.

293 Due to the annealing process, the nanocrystals of porcine and bovine bones suffer a

294 coalescence process $(20,35)$ increasing their size. In this case, the new particles are from

29552 to $70 \mathrm{~nm}$ in length and 36 to $45 \mathrm{~nm}$ in width. The calcination process for the human

296 samples does not follow the same trend, since for these, the nanocrystals coalesce forming

297 sub-micron crystals $190 \mathrm{~nm}$ length and $173 \mathrm{~nm}$ width. The difference in size the crystals

298 reached after the annealing process for bovine and porcine samples as compared to that

299 obtained for human bones is related to their respective chemical composition and age.

300 Rendon and Serna (36) studied the effect of the crystal size on the infrared spectra of

301 hematite formed between 250 to $600{ }^{\circ} \mathrm{C}$; they showed that the differences in the infrared

302 spectra are originated by variations in the size and shape of the particles from nanoparticle

303 to microparticle systems. Through a detailed analysis of the IR bands, the bandwidth of

304 bovine, porcine, and human raw samples exhibited different behaviors in comparison to

305 calcinated samples. This effect is originated in part by the growth of the crystals size and to

306 the calcination process changing the structural properties of these BIO-HAp $(20,35)$. Here 
307

308

309

310

311

312

is important to point out that if the crystal size increases, the number of vibrational states on the surface decreases, then the FWHM of the samples is not influence by these states and becomes narrow and well defined. Furthermore, taking into consideration the arguments stated above on the difference in coordination number for atoms in the crystals and on the surface, the position and width of Raman bands are expected to change when crystals of nano size and micro size are analyzed and compared.

The Raman FWMH measured showed a clear difference between nano and micro-sized crystals. The model to calculate the Raman spectra of a material assumes that the crystal is infinite, however advances in nanoscience and nanotechnology have made necessary to include finite size effects on the Raman and IR spectra to explain their features. The interpretation of the spectra plays a primary role in the case of nanoparticles as quantum dots $(7,8)$. The analysis of the experimental Raman spectra is done considering the confinement effect due to the finite size of the nanoparticles. The broadening of phonon peaks is governed by factors such as varied sizes, orientation, and shapes of the nanoparticles. Traditionally high FWHM values have been associated to crystals with low crystalline quality. However, in the case of biogenic hydroxyapatite nanocrystals, the high values they show are associated to size effects. Here, it is necessary to point out that the decrease in the $v_{1} \mathrm{PO}_{4}{ }^{3-} \mathrm{FWHM}$ due to the incineration process is due to an increase in the crystallites size as was demonstrated by Londoño-Restrepo et al. (1) and measured in this work through SEM, as is shown above. Thus, it is not the result of the improvement of the crystalline quality of the HAp crystals, as it is frequently mentioned in the literature. 


\section{CONCLUSIONS}

331 Infrared and Raman spectroscopy were used to analyze the crystalline structure of raw and

332 calcined at $720^{\circ} \mathrm{C}$ of human, bovine and porcine bones. We have shown that defatted and

333 deproteinized raw human, bovine, and porcine bones exhibit crystalline hydroxyapatite

334 structures as nanoplates displaying a high crystalline quality, as opposed to common claims

335 about the low crystalline quality biogenic hydroxyapatites have. This fact was made evident

336 by TEM measurements. Besides, a calcination process at $720{ }^{\circ} \mathrm{C}$ to human, bovine and

337 porcine bones gave, as a result, the formation of sub-micron crystals, and the infrared and

338 Raman spectra of raw and calcined samples displayed marked differences. Considering that

339 raw samples are nanoplates with high crystalline quality, the calculation of the crystalline

340 percent in the present form does not make any physical sense.

342 Author Contributions All authors have contributed significantly to the manuscript. Study

343 design: S.M.L.R. and M.E.R.G. Acquisition and analysis of data: M.A.M.S., L.F.Z., and

344 R.J.C. Interpretation of data: All authors. Drafting of the manuscript: M.E.R.G. and

345 S.M.L.R. Critical revision of the manuscript for important intellectual content: All authors.

346 Conflict of interest

347 This manuscript was completed through the contributions of all authors and there is not any

348 kind of conflict.

\section{$349 \quad$ Funding Sources}

350 This work was supported by the PAPIIT-Universidad Nacional Autónoma de Mexico,

351 project number IN112317. Luis F. Zubieta-Otero and Sandra M. Londoño-Restrepo thank 
353 support of their postgraduate studies. Authors thank M. en Q. Alicia del Real for her

354 technical SEM support, and Carolina Muñoz from CGEO-UNAM for the ICP

355 determinations.

\section{References}

1. Londoño-Restrepo, S. M., R. Jeronimo-Cruz, E. Rubio-Rosas, and M. E. properties of bio hydroxyapatite from bovine bone. J. Mater. Sci. Mater. Med. 29:52-57. physicochemical properties of bio and commercial Hydroxyapatite. Curr. Appl. Phys. 13:1383-1390.

3. Ooi C. Y., M. Hamdi, and S. Ramesh. 2007. Properties of hydroxyapatite produced by annealing of bovine bone. Ceram. Int. 33:1171-1177.

4. Ramirez-Gutierrez C. F., A. F. Palechor-Ocampo, S. M. Londoño-Restrepo, B. M. Millán-Malo, and M. E. Rodriguez-García. 2016. Cooling rate effects on thermal, structural, and microstructural properties of biohydroxyapatite obtained from bovine bone. J. Biomed. Res. Part. B. 104(2):339-344. 
6. Sathyavathi R., A. Saha, J. S. Soares, N. Spegazzini, S. McGee, R. R. Dasari, M.

Fitzmaurice, and I. Barman. 2015. Raman spectroscopic sensing of carbonate intercalation in breast microcalcifications at stereotactic biopsy. Sci. Rep. 5:99079919.

7. Ehbrecht E., H. Ferkel, and F. Huisken. 1995. Deposition and analysis of silicon clusters generated by laser-induced gas phase reaction. J. Appl. Phys. 78:53025306.

8. Ehbrecht M., B. Kohn, F. Huisken, M. A. Laguna, and V. Paillard. 1997. Photoluminescence and resonant Raman spectra of silicon films produced by sizeselected cluster beam deposition. Phys. Rev. B. 56:6958-6964.

9. Li G. H., K. Ding, Y. Chen, X. H. Han, and Z. P. Wang. 2000. Photoluminescence and Raman scattering of silicon nanocrystals prepared by silicon ion implantation into $\mathrm{SiO}_{2}$ films. J. Appl. Phys. 88:1439-1442.

10. Sirenko A. A., J. R. Fox, I. A. Akimov, X. X. Xi, and Z. Liliental-Weber. 2000. In situ Raman scattering studies of the amorphous and crystalline Si nanoparticles. Solid. State. Com. 113:553-559.

11. Dogan I., and M. C. M. Van de Sanden. 2013. Direct characterization of nanocrystal size distribution using Raman Spectroscopy. J. Appl. Phys. 114:134310-134318.

12. Swamy V., A. Kuznetsov, L. S. Dubrovinsky, R. A. Caruso, G. G. Shchukin, and B. C. Muddle. Finite-size and pressure effects on the Raman spectrum of nanocrystalline anatase $\mathrm{TiO}_{2}$. Phys. Rev. B. 71:184302-184311.

13. Gao Y., X. Zhao, P. Yin, and F. Gao. Size-dependent Raman shifts for nanocrystals. Sci. Rep. 6:20539-20545. 
14. Wopenka B., and J. D. Pasteris. 2005. A mineralogical perspective on the apatite in bone. Mat. Sci. Eng. C. 25:131-143.

401

15. Gouadec G., and P. Colomban. 2007. Raman Spectroscopy of Nanomaterials: How Spectra Relate to disorder, particle size and mechanical properties. Prog. Cryst. Growth. Charact. Mater. 53(1):1-56.

16. Awonusi A., M. D. Morris, and M. M. Tecklenburg. 2007. Carbonate assignment and calibration in the Raman spectrum of apatite. Calcif. Tissue. Int. 81:46-52. of the Raman line broadening on carbonation in synthetic hydroxyapatite. J. Raman. Spectrosc. 19:13-21. approaches for quantification of bone mineral crystallinity using transmission fourier transform infrared (FT-IR), attenuated total reflection (ATR) FT-IR, and Raman Spectroscopy. App. Spect. 72(11):1581-1593.

19. Rey C., O. Marsan, C. Combes, C. Drouet, D. Grossin, and E. Sarda. 2014. Characterization of Calcium Phosphates Using Vibrational Spectroscopies. In Advances in Calcium Phosphate Biomaterials, 2nd Vol. B. Ben-Nissan, editor. Springer Series in Biomaterials Science and Engineering, Berlin, pp. 229-266. 20. Londoño-Restrepo S. M., C. F. Ramirez-Gutierrez, A. del Real, E. Rubio-Rosas, and M. E. Rodriguez-García. 2016. Study of bovine hydroxyapatite obtained by calcination at low heating rates and cooled in furnace air. J. Mat. Sci. 51(9):4431444. 
time on the thermal, structural, morphological, and vibrational properties of hydroxyapatite derived from pig bone. Cer. Inter. 7:43(10):7552-7559. thermal and XRD characterization of hydroxyapatite from new natural sources, Spectrochim. Acta. A. Mol. Biomol. Spectrosc. 83:56-60. Temperature dependent structural and vibrational properties of hydroxyapatite: A theoretical and experimental study. Ceram. Int. 43:15899-15904. natural hydroxyapatite extracted from bovine cortical bone ash. J. Ceram. Process. Res. 10(2):129-138. nanohydroxyapatite with collagen and poly (vinyl alcohol). Colloids. Surf. B. Biointerfaces. 48(1):42-49. J. Nanoparticle. Res. 15:1373-1389.

27. Lin Z., R. Hu, J. Zhou, Y. Ye, Z. Xu, and C. Lin. 2017. A further insight into the adsorption mechanism of protein on hydroxyapatite by FTIR-ATR spectrometry, Spectrochim. Acta A Mol. Biomol. Spectrosc. 173:527-531. 
29. Mandair G. S., and M. D. Morris. 2015. Contributions of Raman spectroscopy to the understanding of bone strength. Bonekey Rep. 4(620):1-8.

30. Szcześ A., Y. Yan, E. Chibowski, L. Holysz, and M. Banach. 2018. Properties of natural and synthetic hydroxyapatite and their surface free energy determined by the thin-layer wicking method. Appl. Surf. Sci. 434:1232-1238.

31. Kumar G. S., G. Karunakaran, E. K. Girija, E. Kolesnikov, N. Van Minh, M. V. Gorchekov, and D. Kuznetsov. 2018. Size and morphology-controlled synthesis of mesoporous hydroxyapatite nanocrystals by microwave-assisted hydrothermal method. Ceram. Int. 44(10):11257-11264.

32. Penel G., C. Delfosse, M. Descamps, and G. Leroy. 2005. Composition of bone and apatitic biomaterials as revealed by intravital Raman microspectroscopy. Bone. 36(5):893-901.

33. Crane N. J., V. Popescu, M. D. Morris, P. Steenhuis, M. A. Jr. Ignelzi. 2006. Raman spectroscopic evidence for octacalcium phosphate and other transient mineral species deposited during intramembranous mineralization. Bone. 39(3):434-442.

34. Patel S., S. Wei, J. Han, and J. Gao. 2015. Transmission electron microscopy analysis of hydroxyapatite nanocrystals from cattle bones. Mater. Charact. 109:7378.

35. Aguilera-Barreiro M. D. L. A., J. A. Rivera-Márquez, H. M. Trujillo-Arriaga, J. A. Tamayo-Orozco, E. Barreira-Mercado, and M. E. Rodríguez-García. 2013. Intake of dehydrated nopal (Opuntia ficus indica) improves bone mineral density and calciuria in adult Mexican women. Food Nutr. Res. 57(1):19106-19120.

36. Rendon J. L., and C. J. Serna. 1981. IR spectra of powder hematite: effects of particle size and shape. Clay. Miner. 16:375-382. 


\section{FIGURE LEGENDS}

472 Figure 1. Thermal profile for powder bones incinerated at $720^{\circ} \mathrm{C}(\mathrm{B}-720, \mathrm{P}-720$, and $\mathrm{H}-$

473 720).

474 Figure 2. TEM images of the defatted and deproteinized porcine (A-D), bovine (E-H) and

475 human (I-L) bones.

476 Figure 3. Mineral composition of defatted and deproteinized human, bovine and porcine

477 powder bone. (A) Content of major minerals, $\mathrm{P}$ and $\mathrm{Ca}$ and $\mathrm{Ca} / \mathrm{P}$ ratio. (B) Content of

478 minor minerals: $\mathrm{Na}, \mathrm{Mg}, \mathrm{K}, \mathrm{Fe}, \mathrm{Al}$, and $\mathrm{Zn}$.

479 Figure 4. Infrared spectra of raw and calcined samples from human, bovine and porcine

480 bones, as well as synthetic Hap, in the spectral ranges: (A) 3700-3000 cm-1, (B) 2955-2820

$481 \mathrm{~cm}^{-1}$, (C) $1750-1300 \mathrm{~cm}^{-1}$, (D) $1200-450 \mathrm{~cm}^{-1}$, and (E) FWHM of $560 \mathrm{~cm}^{-1}$ band for all

482 samples analyzed.

483 Figure 5. Raman spectra of raw and calcined samples from human, bovine and porcine

484 bones, as well as synthetic Hap, in the spectral ranges: (A) 2000-1200 cm-1, (B) 1100-1020

$485 \mathrm{~cm}^{-1}$, (C) $985-940 \mathrm{~cm}^{-1}$, (D) $650-400 \mathrm{~cm}^{-1}$, and (E) FWHM of $960 \mathrm{~cm}^{-1}$ band for all samples 486 analyzed.

487 Figure 6. SEM image s of (A) P-720, (B) B-720, and (C) H-720. 


\section{TABLE CAPTIONS}

491 Table 1. Observed infrared band positions for raw bones, sintered hydroxyapatites, and

492 Sigma Aldrich.

493 Table 2. Observed infrared band positions for raw bones, sintered biogenic

494 hydroxyapatites, and Sigma Aldrich. 